\title{
Volatile Nickel Aminoalkoxide Complexes as Liquid Precursors for Non-volatile Memory Device of NiO Films by ALD
}

\author{
Taek-Mo Chung, Sun Sook Lee, Wontae Cho, Minchan Kim, Young Kuk Lee, Jin-Ha Hwang, Ki-Seok An, and Chang Gyoun Kim* \\ Advanced Materials Division, Korea Research Institute of Chemical Technology, Daejeon 305-600, Korea. E-mail: cgkim@krict.re.kr \\ † Department of Materials Engineering, Hongik University, Seoul 121-791, Korea \\ Received December 13, 2010, Accepted January 6, 2011
}

Key Words : Nickel oxide, Precursor, ReRAM, ALD, Aminoalkoxide

Recently, NiO film of metal-oxide-metal (MOM) structure ${ }^{1 \mathrm{a}}$ has drawn much attention because it shows reproducible resistance switching phenomena applicable to next generation nonvolatile resistive random access memory (ReRAM) device. The resistance switching phenomenon, that is, a drastic change in resistance between a high-resistance state (OFFstate) and low resistance state (ON-state) in current-voltage (I-V) characteristic of MOM structure, has been observed in binary oxides such as $\mathrm{NiO},{ }^{1} \mathrm{TiO}_{2},{ }^{2} \mathrm{Nb}_{2} \mathrm{O}_{5},{ }^{3} \mathrm{Cr}$-doped $\mathrm{SrZrO}_{3},{ }^{4} \mathrm{Pr}_{1-\mathrm{x}} \mathrm{CaMnO}_{3},{ }^{5}$ and chalcogenide semiconductors although exact origin was unsolved. Among these materials, the binary oxide is the first consideration for the application due to the relatively simple fabrication process.

In the case of a device fabrication, the self-limiting process of atomic layer deposition (ALD) may be very important for the growth of $\mathrm{NiO}$ films because the expected structure of ReRAM device requires the filling process of $\mathrm{NiO}$ on the hole or trench-patterned 3-dimensional substrates. Therefore, it is worthwhile to find the optimal ALD process for $\mathrm{NiO}$ film growth by using suitable Ni precursors. In general, most of $\mathrm{Ni}$ compounds are in solid state at room temperature although highly volatile liquid precursor is highly desirable to obtain conformal film qualities in ALD processes.

A number of nickel precursors have been synthesized and examined for preparing $\mathrm{Ni}$ and $\mathrm{NiO}$ films using metal organic chemical vapor deposition (MOCVD) and ALD during the past years. The ligands for the nickel precursors are carbonyl, ${ }^{6}$ $\beta$-diketonates, ${ }^{7}$ cycolpentadienyl, ${ }^{8}$ and alkoxides, ${ }^{9} N, N$ '-dialkylacetamidinates, ${ }^{10}$ phosphites, ${ }^{11}$ and combination of cyclopentadienyl and allyl. ${ }^{12}$ Many nickel precursors have their drawbacks such as low volatilities and toxicity, and carbon contaminations in the prepared films. Except $\mathrm{Ni}(\mathrm{CO})_{4}$, all of them are solids at room temperature, although cyclopentadienylallylnickel for nickel thin films is a liquid at $10{ }^{\circ} \mathrm{C}$. ${ }^{12}$ HubertPfalzgraf et al. prepared a volatile $\mathrm{Ni}\left(\mathrm{OCHMeCH} \mathrm{NMe}_{2}\right)_{2}$ which was sublimed at $93-95{ }^{\circ} \mathrm{C}$ under $0.01 \mathrm{mmHg} .{ }^{13}$ Recently, we have synthesized nickel dialkylamino alkoxide complexes $\left[\mathrm{Ni}(\text { dmamp })_{2}, \mathrm{Ni}(\mathrm{emamp})_{2}\right.$, and $\left.\mathrm{Ni}(\text { deamp })_{2}\right]$ which are solids at room temperature but they are volatile and thermally stable. ${ }^{14}$

In this study, novel volatile and liquid nickel precursors were synthesized by using ligands with unsymmetrical substituents and employed with water to deposit $\mathrm{NiO}$ films by ALD. In addition, the resistance switching of $\mathrm{Pt} / \mathrm{NiO} / \mathrm{Pt}$ MIM structure was also investigated.
Metal complexes with low melting point, that is, liquid precursors are highly desirable to keep a constant vapor pressure and to avoid particle problems during the deposition process. As our ongoing studies to develop volatile and stable precursors applicable to chemical deposition processes such as CVD and ALD, we have introduced dialkylamino alkoxide ligands which contain alkoxide and donor-functionalized amino group to saturate the vacant sites of the central metal ion. In particular, we believe that organic disubstituents on $\alpha$-carbon from the hydroxyl group of the dialkylamino alkoxide ligands prevent effectively the metal complexes from forming intermolecular interaction, make the metal complex become monomeric, and result in the improvement of the volatility of the metal precursors. ${ }^{14,15}$

In order to synthesize new liquid nickel complexes by the modification of the ligand of the $\mathrm{Ni}(\mathrm{dmamp})_{2}$, we introduced the concept of unsymmetric configuration on $\alpha$-carbon from the hydroxyl group of the dmamp ligand. We believe that the volatility of metal complex can be improved with unsymmetrically substituted ligands instead of symmetrically substituted ones, due to the less compacted molecular packing originating from the unsymmetrical ligand, which phenomena were already reported in the literature. ${ }^{12,14 a, 16}$ Thus, switching one of two methyl groups to ethyl on the $\alpha$-carbon of the dmamp, deamp, and emamp regardless of changing substituents on dialkylamino group renders an asymmetric carbon to give another dialkylamino alkoxide such as dmamb, deamb, and emamb. Complexation of the new dialkylamino alkoxides with nickel cation resulted in the formation of novel liquid nickel precursors and their volatilities are similar to those of nickel complexes with symmetrical substituents ligands. It should be noted that changing the dialkylamino group with unsymmetrical substituents while the same organic groups exists on the $\alpha$-carbon did not afford liquid metal complexes.

As shown in Figure 1, the metathesis reaction of $\left[\mathrm{Ni}\left(\mathrm{NH}_{3}\right)_{6}\right] \mathrm{Cl}_{2}$ with two equivalents of sodium salts of the dialkylamino alcohol, gave desired nickel precursors in moderate to excellent (see Supporting Information). The compounds were highly soluble in common organic solvents such as $\mathrm{THF}, \mathrm{Et}_{2} \mathrm{O}$, and toluene. NMR spectra and elemental analyses of the products were in good agreement with the suggested structures. Amino alcohols such as dmambH, emambH, and deambH have a chiral center on $\alpha$-carbon and exist as a racemic mixture. Therefore, NMR spectra of their nickel complexes showed 


\begin{tabular}{ccccccc} 
1-a & $\mathrm{Ni}(\text { dmamp })_{2}^{\#}$ & $\mathrm{Me}$ & $\mathrm{Me}$ & $\mathrm{Me}$ & $\mathrm{Me}$ & solid \\
$\mathbf{1 - b}$ & $\mathrm{Ni}(\mathrm{emamp})_{2}^{\#}$ & $\mathrm{Me}$ & $\mathrm{Me}$ & $\mathrm{Me}$ & $\mathrm{Et}$ & solid \\
$\mathbf{1 - c}$ & $\mathrm{Ni}(\text { deamp })_{2}^{\#}$ & $\mathrm{Me}$ & $\mathrm{Me}$ & $\mathrm{Et}$ & $\mathrm{Et}$ & solid \\
$\mathbf{1 - d}$ & $\mathrm{Ni}(\mathrm{dmamb})_{2}$ & $\mathrm{Me}$ & $\mathrm{Et}$ & $\mathrm{Me}$ & $\mathrm{Me}$ & liquid \\
$\mathbf{1 - e}$ & $\mathrm{Ni}(\mathrm{emamb})_{2}$ & $\mathrm{Me}$ & $\mathrm{Et}$ & $\mathrm{Me}$ & $\mathrm{Et}$ & liquid \\
$\mathbf{1 - f}$ & $\mathrm{Ni}(\text { deamb })_{2}$ & $\mathrm{Me}$ & $\mathrm{Et}$ & $\mathrm{Et}$ & $\mathrm{Et}$ & liquid \\
\hline
\end{tabular}

${ }^{\#}$ Ref. 14(b), ${ }^{*}$ at room temperature

Figure 1. Ni(II) dialkylamino alkoxide complexes.

very complex peaks due to the existence of $R-R, R-S$, and $S$ $S$ configurations on square planar geometry of the nickel complexes. ${ }^{14 \mathrm{~b}}$ Moreover all of nickel complexes of those ligands are liquid at room temperature and so it was difficult to grow single crystals to confirm the structure of the metal compounds and to investigate the mixture ratio of the complexes. Distillation temperature of under $10^{-2}$ Torr of the nickel liquid complexes, $\mathrm{Ni}(\mathrm{dmamb})_{2}, \mathrm{Ni}(\mathrm{emamb})_{2}$, and $\mathrm{Ni}(\text { deamb })_{2}$ are 80,90 , and $120{ }^{\circ} \mathrm{C}$, respectively, which increase on the increasing of the size of the substituents on the ligand.

The compound $\mathrm{Ni}(\mathrm{dmamb})_{2}$ is a liquid at room temperature and has the highest volatility among the liquid nickel complexes synthesized in this study, so we chose $\mathrm{Ni}(\mathrm{dmamb})_{2}$ as precursor to make nickel oxide thin films. By using the $\mathrm{Ni}(\mathrm{dmamb})_{2}$ and water, $\mathrm{NiO}$ films were deposited by ALD (see Supporting Information). The thickness measurements of $\mathrm{NiO}$ films with various precursor pulse time, the number of ALD cycle, and substrate temperature indicated that the growth of $\mathrm{NiO}$ film is governed by self-liming ALD mechanism and the growth rate was constantly reached to $\sim 1.4 \AA$ /cycle on $\mathrm{Si}$ substrate under optimal conditions at the substrate temperature of $100-140{ }^{\circ} \mathrm{C}$. XPS, XRD, and AFM data showed the formation of amorphous Ni monoxide film with surface root-mean square (RMS) roughness of about $6.64 \AA$.

Figure 2 shows the cross-sectional SEM image of $\mathrm{NiO}$ film deposited on trench-patterned TaN/Si substrate at $140{ }^{\circ} \mathrm{C}$ with 1000 times of ALD cycle. The SEM image shows fully filled structure on a trench-patterned substrate without any void and indicates that the $\mathrm{NiO}$ film growth by using $\mathrm{Ni}(\mathrm{dmamb})_{2}-\mathrm{H}_{2} \mathrm{O}$ ALD process can be will adopted in the hole- and trench-filling processes of 3-D substrates with excellent conformality, which requires in the fabrication process of ReRAM device.

To investigate the nonvolatile memory characteristics of ALD-grown $\mathrm{NiO}$ film, I-V characteristics of the $\mathrm{Pt} / \mathrm{NiO} / \mathrm{Pt} /$ $\mathrm{SiO}_{2} / \mathrm{Si} \mathrm{MIM}$ structure were investigated. Resistance switching behaviors show transition from high resistance (OFFstate) to low resistance (ON-state) for the $50 \mathrm{~nm} \mathrm{NiO}$ film grown at $140{ }^{\circ} \mathrm{C}$ (see Supporting Information). The resistance ratio was about 3 orders of magnitude from OFF- to ONstate. The set and reset voltages were about $1.6 \mathrm{~V}$ and $0.9 \mathrm{~V}$, respectively. The set and reset voltages and the resistance ratio were comparable to those of polycrystalline $\mathrm{NiO}$ films

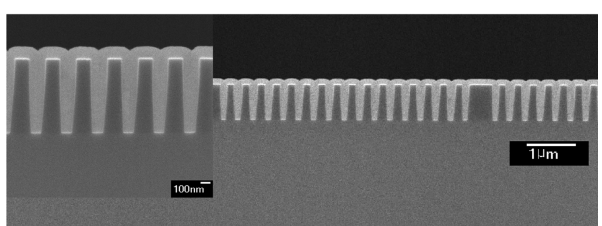

Figure 2. Cross-sectional SEM image of $\mathrm{NiO}$ film deposited on trench-patterned $\mathrm{TaN} / \mathrm{Si}$ substrate at $140{ }^{\circ} \mathrm{C}$.

deposited by other physical deposition techniques.

In conclusion, we have synthesized the highly volatile nickel precursors in a liquid state by introducing the concept of unsymmetric configuration on ligands, and employed $\mathrm{Ni}(\mathrm{dmamb})_{2}$ to deposit $\mathrm{NiO}$ thin films by ALD with water as other reactant. Completely filled $\mathrm{NiO}$ film structure on a trench-patterned TaN/Si substrate was realized without any void by using $\mathrm{Ni}(\mathrm{dmamb})_{2}-\mathrm{H}_{2} \mathrm{O}$ ALD process and typical resistance switching behavior of $\mathrm{Pt} / \mathrm{NiO} / \mathrm{Pt}$ capacitor structure was also observed. These results suggest that the well designed chemistry fulfilling the needs of device process can greatly contribute to the next generation information technology (IT) devices.

Acknowledgments. This research was supported by the Converging Research Center Program through the Ministry of Education, Science and Technology (2010K000976).

\section{References}

1. (a) Seo, S.; Lee, M. J.; Seo, D. H.; Jeong, E. J.; Suh, D.-S.; Joung, Y. S.; Yoo, I. K. Appl. Phys. Lett. 2004, 85, 5655. (b) Oka, K.; Yanagida, T.; Nagashima, K.; Tanaka, H.; Kawai, T. J. Am. Chem. Soc. 2009, $131,3434$.

2. (a) Choi, B. J.; Jeong, D. S.; Kim, S. K.; Choi, S.; Oh, J. H.; Rohde, S. C.; Kim, H. J.; Hwang, C. S.; Szot, K.; Waser, R.; Reichenberg, B.; Tiedke, S. J. Appl. Phys. 2005, 98, 033715. (b) Rohde, C.; Choi, B. J.; Jeong, D. S.; Choi, S.; Zhao, J.-S.; Hwang, C. S. Appl. Phys. Lett. 2005, 86, 262907.

3. Hiatt, W. R.; Hickmott, T. W. Appl. Phys. Lett. 1965, 6, 106.

4. Watanabe, Y.; Bednorz, J. G.; Bietsch, A.; Gerber, C.; Widmer, D.; Beck, A.; Wind, S. J. Appl. Phys. Lett. 2001, 78, 3738.

5. (a) Asamitsu, A.; Tomioka, Y.; Kuwahara, H.; Tokura, Y. Nature 1997, 388, 50. (b) Liu, S. Q.; Wu, N. J.; Ignatiev, A. Appl. Phys. Lett. 2000, 76, 2749.

6. Carlton, H.; Oxle, J. A.I.Ch.E. 1967, 13, 86.

7. Buono-Core, G. E.; Tejos, M.; Alveal, G.; Hill, R. H. J. Mater. Sci. 2000, 35, 4873.

8. Hunde, E. T.; Watkins, J. J. Chem. Mater. 2004, 16, 498.

9. Utriainen, M.; Kröger-Laukkanen, M.; Niinistö, L. Mater. Sci. Eng. $B$ 1998, 54, 98 .

10. Lim, B. S.; Rahtu, A.; Gordon, R. G. Nat. Mater. 2003, $2,749$.

11. Choi, H.; Park, S.; Kim, T. H. Chem. Mater. 2003, 15, 3735.

12. Kada, T.; Ishikawa, M.; Machida, H.; Ogura, A.; Ohshita, Y.; Soai, K. J. Crystal Growth 2005, 275, e1115.

13. Werndrup, P.; Gohil, S.; Kessler, V. G.; Kritikos, M.; Hubert-Pfalzgraf, L. G. Polyhedon 2001, 20, 2163.

14. (a) Yang, T. S.; Cho, W.; Kim, M.; An, K.-S.; Chung, T.-M.; Kim, C. G.; Kim, Y. J. Vac. Sci. Technol. A 2005, 23, 1238. (b) Yoo, S. H.; Choi, H.; Kim, H.-S.; Park, B. K.; Lee, S. S.; An, K.-S.; Lee, Y. K.; Chung, T.-M.; Kim, C. G. accepted for publication in Eur. J. Inorg. Chem.

15. (a) Park, J. W.; Jang, H. S.; Kim, M.; Sung, K.; Lee, S. S.; Chung, T.-M.; Koo, S.; Kim, C. G.; Kim, Y. Inorg. Chem. Commun. 2003, 7, 463. (b) Kim, M.; Jang, H. S.; Chung, T.-M.; Kim, C. G.; Kim, Y.; Cho, B. R. Bull. Korean Chem. Soc. 2005, 26, 829.

16. Park, K.-H.; Marshall, W. J. J. Am. Chem. Soc. 2005, 127, 9330. 